\title{
12. RKR 2019: Die ganze Bandbreite der Radiologie
}

Sehr geehrte Damen und Herren,

das vielfältige Spektrum der Radiologie in einem kompakten Fortbildungskongress vereint: Auch 2019 wird der 12. RadiologieKongressRuhr (RKR) wieder seine Stärken ausspielen.

Verankert in der Region, mit bundesweiter Anziehungskraft, versammelt der Kongress hervorragende Referenten und Referentinnen, die ihr Wissen aus Diagnostik und Therapie in organbezogenen Themenblöcken weitergeben. Ob Thoraxradiologie, Neuroradiologie oder Mammadiagnostik: Beim RKR ist für alle Fortbildungsbedarfe Platz. Stärker noch als bisher werden die Themen in Form eines festen Curriculums aufgebaut, auf das auch die künftigen Ruhrkongresse aufbauen werden. Ziel ist ein über alle Ruhrkongresse hinweg aneinander anknüpfendes Programm, das vom Grundlagen- bis zum Spezialwissen für alle Lernenden etwas bietet. Apropos Lernen: Wenn etwas schiefgeht, ist der Aha-Effekt manchmal doch der größte. Deshalb präsentiert der RKR zu seiner 12. Ausgabe ein neues Format: In „Meine schönsten Fehler“ sprechen Experten über ihre Fall-Fails und diskutieren mit den Teilnehmern.

Nach dem gelungenen Auftakt ist der RKR auch 2019 wieder in den Dortmunder Westfalenhallen zu Gast. Die exzellente Erreichbarkeit aus Nordrhein-Westfalen und der ganzen Bundesrepublik, die moderne Kongresstechnik und das flexible und großzügige Raumkonzept kommen damit wieder zum Tragen.

Die ganze Bandbreite der Radiologie an einem Ort, mit ausreichend Raum und Zeit für den persönlichen Austausch: Kommen Sie miteinander ins Gespräch beim RadiologieKongress Ruhr!

Ich wünsche uns allen einen erfolgreichen und spannenden Kongress.
Mit den besten Grüßen

Ihr
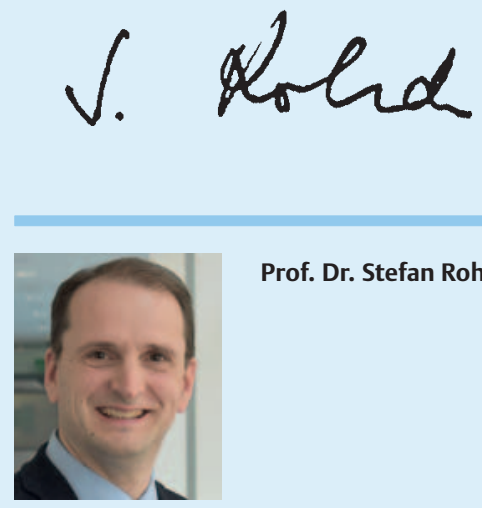

Prof. Dr. Stefan Rohde

\section{Anreise \& Kongresscatering}

Praktische Tipps zur Anreise mit der Bahn, dem Auto oder dem Flugzeug sowie zur Orientierung vor Ort finden Sie unter www.radiologiekongressruhr.de > Informationen

Das Kongresscatering ist auch in diesem Jahr wieder im Ticketpreis inklusive. Es umfasst ein leichtes Mittagessen und kalte Getränke an allen Kongresstagen. 

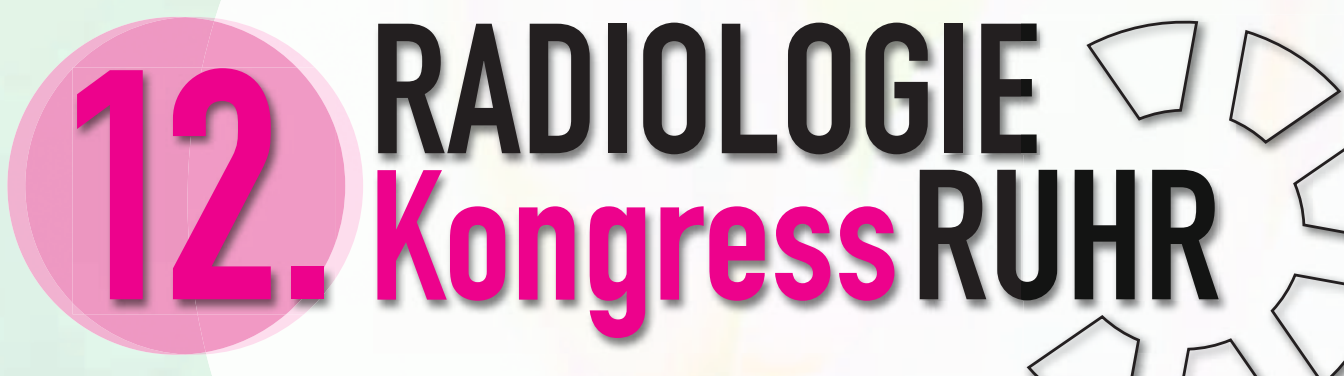
Kongress RUHR

JAHRESKONGRESS DER RHEINISCH-WESTFÄLISCHEN RÖNTGENGESELLSCHAFT e.V.

7.- 8. Nov. 2019

Kongresszentrum

Westfalenhallen Dortmund

www.radiologiekongressruhr.de

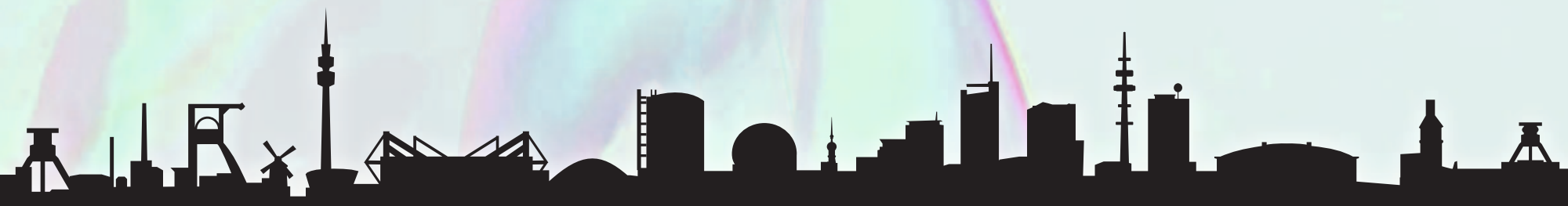

